\title{
Doğrudan Yabancı Sermaye Yatırımlarının Kurumsal Belirleyicileri: OECD Ülkeleri Örneği
}

\author{
Institutional Determinants of Foreign Direct Investment: Evidence from OECD Countries
}

\section{Seyfettin ARTAN ${ }^{1}$, Pınar HAYALOĞLU²}

\section{ÖZET}

Doğrudan yabancı sermaye yatırımlarının ekonomik ve kurumsal belirleyicileri 29 OECD ülkesi için analiz edilmiştir. ÇaIışmada politik riski oluşturan ve ülkelerin kurumsal kaliteleri hakkında bilgi veren hükümet istikrarı, yatırım profili, yolsuzluk, kanun ve düzen, bürokratik kalite gibi on iki alt bileşen kullanılmıştır. Elde edilen sonuçlara göre; OECD ülkelerinde doğrudan yabancı sermaye yatırımlarının temel belirleyicileri ekonomik göstergelerden ziyade hükümet istikrarı, sosyoekonomik durum, yatırım profili, iç karışıklık, askeriyenin politikaya etkisi, dinsel gerilimler, kanun ve düzen, etnik gerilimler ve bürokratik kalite gibi kurumsal göstergelerdir. Elde edilen bu sonuç, iyi bir kurumsal yapının OECD ülkelerinde doğrudan yabancı sermaye yatııılarını çekmede önemli bir rol oynadığını ortaya koymaktadır.

Anahtar Kelimeler: Doğrudan Yabancı Sermaye Yatırımları, Kurumsal Yapı, Politik Risk.

\section{GíRiş}

Kurumsal yapı, son yıllarda başta büyüme teorileri olmak üzere birçok teoride belirleyici öneme sahip bir faktör haline gelmiştir. Özellikle 1990'I yıllardan bu yana kurumsal yapı ve iktisadi büyüme ilişkisi araştırmacıların ilgisini çeken bir konu haline gelmiş ve söz konusu ilişkiyi ele alan literatür (Acemoğlu, 2009; Acemoğlu ve diğerleri, 2003; Acemoğlu ve Robinson, 2012; Easterly, 2005; Dawson, 2003, 2010; De Haan ve Siermann, 1995, 1998; Knack ve Keefer, 1997, Hall ve Jones, 1999) giderek gelişmiştir. Benzer şekilde son yıllarda dikkat çeken bir olgu da kurumsal yapının, doğrudan yabancı sermaye yatırımlarının belirleyicilerini açıklamaya yönelik çalışmalarda da odak noktası haline gelmiş olmasıdır. Çalışmalarında kurumların niteliğine odaklanan araştırmacılara göre, kurumların kalitesi ülkeye giren doğrudan yabancı yatırımların önemli bir belirleyicisidir.

Dünyada özellikle küreselleşme ile birlikte doğrudan yabancı sermaye yatırımlarının boyutu önemli ölçüde artmıştır. Doğrudan yabancı sermaye yatırımlarının ekonomik etkileri, doğrudan yabancı serma-

\begin{abstract}
Economic and institutional determinants of foreign direct investment are analyzed for 29 OECD countries. In the study, twelve subcomponents are used such as investment profile, corruption, law and order, bureaucratic quality and government stability which can give information about political risk and institutional quality of the countries. According to results; main determinants of foreign direct investment in OECD countries are institutional factors like government stability, socioeconomic condition, investment profile, internal conflict, military in politics, religious tensions, law and order, ethnic tensions and bureaucratic quality rather than economic determinants. Our findings indicate that a good institutional structure plays an important role in attracting foreign direct investment in OECD countries.
\end{abstract}

Keywords: Foreign Direct Investment, Institutional Structure, Political Risk

yenin hangi kanal ya da kanallarla ülkeye girdiğine ve hangi kesimi etkilediğine bağı olarak değişmekle birlikte; literatürde doğrudan yabancı sermaye yatırımlarının ev sahibi ülke ekonomisini pozitif etkilediği genel olarak kabul görmektedir. Şöyle ki; doğrudan yabancı sermaye yatırımları teknoloji ve bilgi transferini kolaylaştırmakta, yurtiçi firmaların gelişmesine ve yeniden yapılandırılmasına yardım etmekte, uluslararası entegrasyona katkı sağlamakta ve yurtiçi beşeri sermaye oluşumunu desteklemektedir. Doğrudan yabancı sermaye yatırımları bu özellikleriyle ev sahibi ülkelerde ekonomik büyümeyi hızlandıııcı bir rol oynamaktadır Bu durum, ülkelerin son yıllarda doğrudan yabancı sermaye yatırımlarını kendi ülkelerine çekebilmek için yoğun bir rekabet içine girmelerine yol açmıştır.

Bu doğrultuda, sermaye akımlarının en istikrarlı bileşenlerinden olan doğrudan yabancı sermaye yatırımları, uluslararası finansal bütünleşmenin önemli bir aracı olarak dünya ekonomisine yön veren faktörlerin başında gelmektedir. Sermayenin küreselleşmesiyle birlikte, sermaye ihtiyacı olan ülkeler doğrudan 
yabancı yatırım çekebilmek için yatırım ortamlarını iyileştirmek üzere politika ve stratejiler benimsemektedirler. Diğer yandan Anghel (2005: 2-3); uluslararası finansal bütünleşmenin, yalnızca iyi makroekonomik politikalar değil aynı zamanda iyi bir yurtiçi yönetim altında, büyüme için yararlı olabileceğini vurgulamaktadır. Örneğin, fiziki sermaye ve karlar üzerindeki mülkiyet haklarının düşük düzeyde korunması yatırımlar için ciddi bir engel oluşturabilir. Benzer şekilde, yüksek derecedeki yolsuzluk ve yavaş işleyen bürokrasi bir ülkede yatırım sürecini yavaşlatabilir, izin ve lisansların dağıtımını geciktirebilir. Bu doğrultuda iyi bir yönetime sahip ülkelerin doğrudan yabancı yatırımları daha fazla çekme eğiliminde olduğu söylenebilir. Bir diğer deyişle, günümüzde mali küreselleşmeden fayda elde etmek büyük ölçüde kurumsal ve makroekonomik çevrenin kalitesine bağlıdır.

Daniele ve Marani (2006: 17), kurumların doğrudan yabancı yatırımlar üzerindeki etkisinin üç farklı kanalla gerçekleştiğini belirtmektedir. Öncelikle, iyi kurumların varlığı verimliliği arttırmak suretiyle yatırımları teşvik etmektedir. İkinci olarak, iyi kurumlar işlem maliyetlerini azaltarak yatırımları arttırmaktadırlar. Son olarak, doğrudan yabancı yatııımlar genellikle yüksek batık maliyetleri içerdiğinden, iyi kurumların varlığı (mülkiyet haklarının korunması, sosyal ve politik istikrar, hukukun etkinliği gibi) çok uluslu firmalara güvenilir bir ortam sağlayarak yatırımları attırmaktadır. Benassy-Quere vd. (2007: 764)'ne göre, kurumsal yapı ve doğrudan yabancı yatırımlar arasındaki bağlantıda kurumlar, verimlilik artışını teşvik eden bir kanal olarak ele alınabilir. Böyle bir bağlantıda iyi kurumlar, daha az belirsizlik ve yüksek getiri beklenen oranları ile karşı karşıya kalan yatırımları teşvik yoluyla kalkınma üzerinde olumlu etkide bulunmaktadır. Özellikle gelişmekte olan ülkelerde doğrudan yabancı yatırımların sermaye oluşumunda çok büyük bir payı olduğundan, iyi kurumlar doğrudan yabancı yatırımları arttırarak, büyüme ve kalkınma üzerinde genel bir etki yaratması bakımından önemli bir kanal olabilmektedir.

Literatürde doğrudan yabancı sermaye yatırımlarının belirleyicilerini analiz eden çalışmalar incelendiğinde iki farklı yaklaşımın ön plana çıktığı görülmektedir. Bunlardan birincisi, doğrudan yabancı sermaye yatırımlarının ekonomik belirleyicileri üzerine odaklanırken diğeri daha çok ülkedeki bürokratik yapı, politik yapı, siyasi istikrar, mülkiyet hakları ve yasal düzen gibi kurumsal faktörlerin önemine vurgu yapmakta- dır. Doğrudan yabancı sermaye yatırımlarının belirleyicilerinin analizinde Barrell ve Pain (1997) ve Culem (1988) ev sahibi ülkedeki pazarın büyüklüğü; Billington (1999), Sin ve Leung (2001) ve Moosa (2009) ekonomik büyüme düzeyi; Moore (1993), Konings ve Murphy (2006) ve Bellak vd. (2008) işgücü maliyetleri; Noorbakhsh vd. (2001) Azemar ve Desbordes (2009) beşeri sermaye; Edwards (1990), Sekkat ve Veganzones-Varoudakis (2007), Campos ve Kinoshita (2008) dışa açıklık düzeyinin etkilerini analiz etmişlerdir. $\mathrm{Bu}$ çalışmalardan elde edilen bulgular, doğrudan yabancı sermaye yatırımlarının daha çok pazarın büyük olduğu, ekonomik büyüme hızının ve beşeri sermayenin yüksek olduğu ve işgücü ücretlerinin düşük olduğu dışa açık ekonomileri tercih etme eğiliminde olduğunu göstermektedir.

Diğer yandan ikinci grupta yer alan ve kurumsal yapının doğrudan yabancı sermaye yatıımlarının belirleyicisi olup olmadığını test eden çalışmalara az sayıda da olsa rastlamak mümkündür. Bu çalışmalardan Grogan ve Moers (2001), Anghel (2005), Busse ve Hefeker (2007) ve Antonakakis ve Tondl (2011), ev sahibi ülkedeki mülkiyet hakları düzeyi, hukukun üstünlüğü, yolsuzluk ve hükümetin etkinliği gibi kurumsal faktörlerin doğrudan yabancı sermaye yatırımları üzerindeki etkilerini test etmişlerdir. Elde edilen ortak bulgu; mülkiyet haklarının korunduğu, hükümetin görevlerini etkin şekilde yürüttüğü, bürokratik engellerin olmadığı ve yolsuzluğun düşük olduğu, bir başka deyişle iyi kurumlara sahip ekonomilerde belirsizliğin ortadan kalkacağı ve bu durumun özellikle doğrudan yabancı sermaye yatırımları için elverişli bir ortam yaratacağı şeklindedir.

Bu çalışmanın amacı; doğrudan yabancı sermaye yatırımlarının ekonomik ve kurumsal belirleyicilerini, gruba son yıllarda üye olan 5 ülke' hariç 29 OECD (Organisation for Economic Co-operation and Development) ülkesi ${ }^{2}$ için analiz etmektir. Panel veri analiz yönteminin kullanıldığı çalışmada 1990-2012 dönemine ait yıllık verilerden yararlanılmıştır. Az sayıda kurumsal gösterge kullanarak doğrudan yabanCI sermaye yatırımlarının belirleyicilerini analiz eden literatürdeki mevcut çalışmalardan farklı olarak bu çalışmada; politik riski oluşturan ve ülkelerin kurumsal kaliteleri hakkında bilgi veren hükümet istikrarı, yatırım profili, yolsuzluk, kanun ve düzen, bürokratik kalite gibi on iki alt bileşenden yararlanılmıştır. Her bir kurumsal gösterge ayrı ayrı modellenerek kurumsal göstergeler ile doğrudan yabancı sermaye yatırımları 
arasında bir ilişki olup olmadığı, varsa hangi kurumsal göstergenin doğrudan yabancı sermaye yatırımları üzerindeki etkisinin nispi olarak daha yüksek olduğu araştırılmıştır.

Yedi bölüm olarak hazırlanan çalışmanın ikinci bölümünde OECD ülkelerinde doğrudan yabancı sermaye yatırımlarının boyutu ele alınmıştır. Kurumsal yapının doğrudan yabancı sermaye yatırımları üzerindeki etkilerini analiz eden çalışmaların özetlendiği üçüncü bölümü, analizde kullanılan veri setinin tanıtıldığı ve kullanılan değişkenlere ait tanımlayıcı istatistiklerin yer aldığı dördüncü ve beşinci bölümler takip etmiştir. Çalışmada kullanılan ekonometrik yöntem ve analiz sonuçlarının yer aldığı altıncı bölümü takiben yedinci bölümde çalışmanın genel bir değerlendirilmesi yapılmıştır.

\section{OECD ÜLKELERINNDE DOĞRUDAN YABANCI SERMAYE YATIRIMLARININ BOYUTU}

Dünyada doğrudan yabancı sermaye yatırımlarının önem kazanmaya başladığı 1990'ı yıllardan itibaren nispi olarak yüksek gelir ve yüksek kurumsallaşmanın etkisiyle OECD ülkelerine yönelik doğrudan yabancı sermaye yatııımlarının bir yükseliş eğilimine girdiği gözlenmektedir. OECD ülkelerine yönelen doğrudan yabancı sermaye yatırımlarının boyutunu analiz etmek üzere hazırlanan Grafik 1'de dünyada, Çin'de ve 29 OECD ülkesindeki doğrudan yabancı ser- maye yatırımlarının 1990-2012 yılları arasındaki seyri yer almaktadır. Grafikten takip edileceği üzere, söz konusu yıllar arasında dünyadaki doğrudan yabancı sermaye yatırımlarının büyük bir kısmı OECD ülkelerine yönelmiştir. Özellikle 2006 yılına kadar dünyadaki doğrudan yabancı sermaye akımlarının yaklaşık $\% 85$ 'lik kısmı OECD ülkelerine gitmiştir. Bu oran 1990 yılında \%88 ve 2000 yılında \%86 olarak gerçekleşmiştir. 2007 yılından sonra OECD ülkelerinin dünyadaki toplam doğrudan yabancı sermaye yatırımlarından aldığı payın düştüğü görülmektedir. Örneğin 2007 yıIında dünya genelindeki doğrudan yabancı sermaye yatııımlarının yaklaşık \%68'lik bir kısmı OECD ülkelerine yapılmışken bu oran 2011 yılında \%51 olarak gerçekleşmiştir. Bu düşüşün, özellikle 2000'li yıllardan sonra düşük işgücü maliyetleri nedeniyle Çin'in, dünya doğrudan yabancı sermaye yatırımlarından aldığı payın artması nedeniyle ortaya çıktığını söyleyebiliriz. Bu yıllarda OECD ülkelerine yönelen doğrudan yabancı sermaye yatırımlarının azalmasının bir diğer nedeni 2008 yılında bütün dünyaya yayılan küresel ekonomik kriz olarak gösterilebilir. Grafikten takip edileceği üzere 2000 yılında dünyadaki doğrudan yabancı sermaye yatırımlarının yaklaşık \%2'si Çin'e gitmekteyken, takip eden yıllarda bu oran sürekli olarak artmış ve 2011 yılında \%15 olarak gerçekleşmiştir. Çin dışarıda tutulduğunda, hala OECD ülkeleri dünya doğrudan yabancı sermaye yatırımlarının büyük bir kısmını çekmektedir.

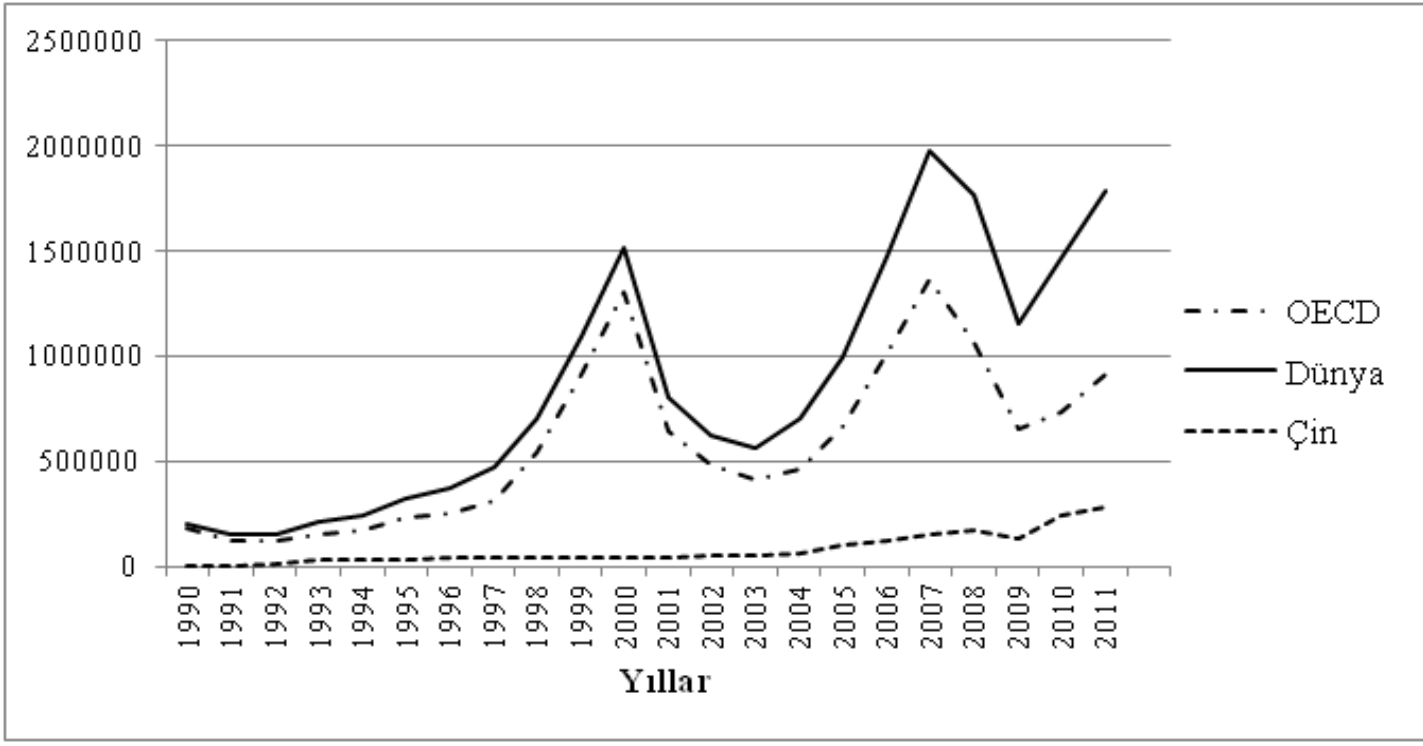

Grafik 1: Dünyada ve OECD Ülkelerinde Doğrudan Yabancı Sermaye Yatırımları (1990-2011, milyon dolar)

Kaynak: OECD Database, 2014 


\section{LITERATÜR ÖZETI}

Doğrudan yabancı sermaye yatırımlarının belirleyicilerinin analizinde daha çok ekonomik faktörlerin etkilerinin test edildiği göze çarpmaktadır. Ancak özellikle son yıllarda yapılan az sayıdaki çalışmada ekonomik faktörlerin yanı sıra kurumsal faktörlerin de doğrudan yabancı sermaye yatırımlarının önemli bir belirleyicisi olduğu kabul edilmektedir. Örneğin; Schneider (1985), 80 az gelişmiş ülkede doğrudan yabancı sermaye yatırımlarının belirleyicilerini araştırdığı çalışmasında siyasi istikrarsızlık ve doğrudan yabancı sermaye yatırımları arasında negatif bir ilişki bulmuştur. Buna göre, siyasi istikrarsızlık doğrudan yabancı sermaye yatırımı girişlerini önemli ölçüde azaltmaktadır. Gastanaga vd. (1998), 49 az gelişmiş ülke için 1970-1995 dönemine ilişkin yatay kesit ve zaman serileri verilerini kullandıkları çalışmalarında; kurumlar vergisi oranları, tarife oranları, uluslararası sermaye akımlarının açıklık derecesi, döviz kuru aksaklıkları, sözleşme uygulama, kamulaştırma riski, bürokratik gecikme ve yolsuzluk gibi çeşitli politik ve kurumsal faktörlerin doğrudan yabancı sermaye yatırımları üzerindeki etkisini araştırmışlardır. Elde edilen sonuçlar, politik ve kurumsal değişkenlerin doğrudan yabancı yatırımlar üzerinde önemli etkilerinin olduğunu göstermektedir.

Demirtaş ve Akçay (2006), kurumsal faktörlerin doğrudan yabancı sermaye yatırımları üzerindeki etkisini araştırdıkları çalışmalarında, gelişmiş ve gelişmekte olan 71 ülkeye ait 1995-2002 yılları verilerini kullanmışlardır. Kurumsal faktör olarak; söz hakkı ve hesap verebilirlik, politik istikrar, bürokrasinin etkinliği, hukukun üstünlüğü, düzenlemelerin kalitesi ve yolsuzlukla mücadele gibi değişkenlerin kullanıldığı çalışmada elde edilen bulgulara göre, kurumlar ile doğrudan yabancı sermaye yatırımları arasında pozitif bir ilişki mevcuttur.

Bir diğer çalışmada Grogan ve Moers (2001), doğrudan yabancı sermaye yatırımlarının kurumsal belirleyicilerini 1990-1998 yıllarını kapsayan dönemde 25 geçiş ekonomisi için araştırmışlardır. Kurumsal yapının belirleyicileri olarak; hukukun üstünlüğü, yatırımlarla ilgili kanunlar, mülkiyet hakları ve sivil toplum değişkenlerinin kullanıldığı çalışmada elde edilen sonuçlar kurumların doğrudan yabancı sermaye yatırımlarının güçlü bir belirleyicisi olduğunu desteklemektedir. Azam vd. (2010), kurumsal faktörlerin ve makroekonomik politikaların doğrudan yabancı sermaye yatırımları üzerindeki etkilerini 1996-2007 yıllarını kapsayan dönemde Güney Asya ülkeleri için araştırmışlardır. Elde edilen sonuçlar, kaliteli kurumsal yapının doğrudan yabancı sermaye yatırımlarını çekmede önemli bir rol oynadığını göstermektedir. Ancak, uygulanan makroekonomik politikaların etkin olmaması kurumların yabancı sermaye çekmedeki rolünü azaltmaktadır.

Sekkat ve Veganzones-Varoudakis (2004), politik risk ve doğrudan yabancı sermaye yatırımları arasındaki ilişkiyi Ortadoğu ve Kuzey Afrika ülkeleri için incelemişlerdir. Uluslararası Ülke Riski Rehberi (ICRG: International Country Risk Guide) endeksinden elde edilen politik risk verisinin kullanıldığı çalışmada, politik risk düzeyindeki düşüşün doğrudan yabancı sermaye yatırımlarını pozitif olarak etkilediği tespit edilmiştir. Busse ve Hefeker (2007), gelişmekte olan 83 ülkede politik riskin doğrudan yabancı sermaye yatırımları üzerindeki etkisini incelemiştir. ICRG'den elde edilen 12 farklı politik risk bileşeninin kullanıldığı çalışmada; hükümet istikrarı, iç ve dış karışıklığın olmaması, bürokratik etkinlik ve kanun ve düzenin korunması değişkenlerinin doğrudan yabancı sermaye yatırımlarının önemli belirleyicileri olduğu saptanmıştır. Khan ve Akbar (2013), 94 ülkeyi ele aldığı çaIışmasında politik risk ve doğrudan yabancı sermaye yatırımları arasındaki ilişkiyi 1986-2009 dönemi için analiz etmiştir. Çalışmada ICRG'den elde edilen; hükümet istikrarı, sosyoekonomik durum, yatırım profili, iç karışıklık, dış karışıklık, yolsuzluk, askeriyenin politikaya etkisi, dinsel gerilimler, kanun ve düzen, etnik gerilimler, demokratik sorumluluk ve bürokratik kalite olmak üzere 12 politik risk bileşeni kullanılmıştır. Yüksek gelirli ülkeler, yüksek orta gelirli ülkeler, düşük orta gelirli ülkeler, düşük gelirli ülkeler ve tüm ülke örneklemi için yapılan analiz sonuçlarından elde dilen bulgular, politik risk göstergelerinin çoğu ile doğrudan yabancı sermaye yatırımları arasında negatif bir ilişki olduğunu ve bu ilişkinin yüksek orta gelirli ülkeler grubunda en güçlü olduğunu göstermektedir.

Anghel (2005); çeşitli kurumsal değişkenlerin doğrudan yabancı sermaye yatırımları üzerindeki etkilerini incelediği çalışmasında, kurumsal yapının göstergesi olarak; politik istikrar, hükümet etkinliği, düzenlemelerin kalitesi, hukukun üstünlüğü, yolsuzluğun kontrolü, mülkiyet hakları, bürokratik engeller ve iş düzenleme endeksi değişkenlerini kullanmıştır. Yapılan analizler sonucu elde edilen bulgular, kurumların doğrudan yabancı sermaye yatırımlarını etkilediğini göstermektedir. Bu sonuca göre, zayıf kurumlara sahip ülkeler daha az doğrudan yabancı sermaye 
yatırımı çekmektedir. Bir diğer çalışmada Daniele ve Marani (2006), Kaufman ve Kraay (2005)'dan elde ettiği yönetişim göstergelerini kullanarak kurumsal yapının doğrudan yabancı sermaye yatırımları üzerindeki etkisini araştırmış ve kurumsal yapının doğrudan yabancı sermaye yatırımı çekmede güçlü bir etkiye sahip olduğunu tespit etmiştir.

Wheeler ve Mody (1992) çalışmalarında, ABD firmalarının doğrudan yabancı sermaye yatırımlarının yer seçim kararları ile politik risk göstergeleri asındaki ilişkiyi incelemiştir. Elde edilen sonuç, politik riskin $A B D$ firmalarının üretim yeri kararlarını belirlemede önemsiz olduğunu göstermektedir. Loree ve Guisinger (1995) çalışmalarında; 1977 ve 1982 yılları verilerini kullanılarak, ABD kökenli çokuluslu şirketlerin yurtdışındaki doğrudan yabancı sermaye yatırımlarının yer seçiminde etkili olan politik ve politik olmayan faktörleri incelemişlerdir. Çalışmada, politik risk düzeyinin doğrudan yabancı sermaye yatırımları üzerindeki etkisinin 1982 yılında negatif iken 1977 yılında hiçbir etkisinin bulunmadığı saptanmıştır. Del Bo (2009) çalışmasında, ABD'nin doğrudan yatırım yaptığı 53 ülke için 1982-2005 yıllarını kapsayan dönemde, kur riski ve politik riskin doğrudan yabancı sermaye yatırımları üzerindeki etkisini incelemiştir. Elde edilen sonuçlar, ev sahibi ülkelerdeki politik riskin ABD'den olan doğrudan yabancı sermaye yatırımları girişini caydırdığını ortaya koymaktadır.

Gast ve Herrmann (2008), 22 OECD ülkesinde 1991-2001 dönemi için, doğrudan yabancı sermaye yatırımlarının belirleyicilerini araştırdıkları çalışmalarında, doğrudan yabancı sermaye yatırımlarının kurumsal belirleyicisi olarak ülke riskini modellerine ilave etmişler ve ülke riskinin doğrudan yabancı sermaye yatırımları üzerinde önemli etkisinin olduğunu tespit etmişlerdir. Gedik (2013), doğrudan yabancı sermaye yatırımlarının belirleyicilerini 11 OECD ülkesinde 1995-2008 arası dönem için araştırmıştır. Doğrudan yabancı sermaye yatırımlarının belirleyicilerini; finansal, ekonomik ve politik ve kurumsal faktörler olmak üzere üçe ayırmış ve bu doğrultuda üç farklı model oluşturmuştur. Politik istikrarın göstergesi olarak; seçim sıklığı, hükümet değişikliği sıklığı ve hükümetteki koalisyon partisi sayısı kullanılmış ve sonuç olarak doğrudan yabancı sermaye yatırımlarının politik ve kurumsal açıdan istikrarsız ortamları tercih etmediğini ortaya konulmuştur.

Hausmann ve Fernandez Arias (2000)'ın çalışmalarında; Kaufmann vd.(1999)'den elde edilen altı farklı kurumsal değişkenin (düzenleyici kalite, hesap verebilirlik, hükümetin etkinliği, yolsuzluk, hukukun üstünlüğü) ve La Porta vd. (1997, 1998a, 1998b)'den elde edilen alacaklı hakları ve hissedar hakları değişkenlerinin doğrudan yabancı sermaye yatırımları üzerindeki etkisi araştırılmıştır. Çalışmada elde edilen bulgular, sermaye akımları içinde doğrudan yabancı sermaye yatırımlarının payının en yüksek olduğu ülkelerin zayıf kurumsal yapıya sahip ülkeler olduğunu desteklemektedir. Ayrıca, doğrudan yabancı sermaye yatırımlarının tersine, sermayenin diğer biçimlerinin kurumsal yapıya daha duyarlı olduğu sonucuna varılmıştır.

Stein ve Daude (2001)'in çalışmasında, OECD ve OECD harici 63 ülkede kurumsal kalitenin doğrudan yabancı sermaye yatırımlarının yer seçimi üzerindeki etkisi araştırılmıştır. Çalışmada kurumsal değişken olarak öncelikle Kaufman vd. (1999)'den elde edilen ifade özgürlüğü ve hesap verebilirlik, siyasi istikrar ve şiddetin olmaması, hükümetin etkinliği, düzenleyici kalite, hukukun üstünlüğü, yolsuzluğun kontrolü ve bu altı değişkenin ortalaması kullanılmış ve ifade özgürlüğü ve hesap verebilirlik dışında diğer tüm değişkenler istatistiki olarak anlamlı bulunmuştur. Daha sonra ICRG'den elde edilen kurumsal değişken setinin kullanıldığı analiz sonuçlarına göre; hükümetin sözleşmeleri tanımaması riski ve kamulaştırma riskinin olmamasının doğrudan yabancı sermaye yatırımları üzerinde özendirici etkisi olduğu tespit edilmişken bürokrasinin kalitesi, yolsuzluk ve hukukun üstünlüğü değişkenleri ile doğrudan yabancı sermaye yatırımları arasında anlamlı bir iliş̧i bulunamamıştır.

Antonakakis ve Tondl (2011)'un çalışmalarında, dört büyük $O E C D$ yatırımcısının (ABD, Almanya, Fransa ve Hollanda), dünyanın farklı bölgelerinde bulunan gelişmekte olan ülkelere olan doğrudan yabancı sermaye yatıımlarının belirleyicileri incelenmiştir. Çalışmada, 1995-2008 döneminde doğrudan yabancı sermaye yatııımı alan 129 ülke, 5 farklı coğrafi bölgeye ayrılmıştır. Analizler sonucunda elde edilen bulgularda, kurumsal faktörler ile doğrudan yabancı sermaye yatırımları arasında güçlü bir ilişki tespit edilememiştir. Buna göre, kurumsal kalite yalnızca Almanya için yer seçim kararlarında güçlü bir belirleyicidir.

\section{VERI SETI VE BEKLENTILER}

OECD ülkelerinde doğrudan yabancı sermaye yatırımlarının ekonomik ve kurumsal belirleyicilerinin analizinde kullanılan değişkenlerin elde edildiği kaynaklar ve değişkenlere ilişkin beklenti işaretleri Tablo 1 'de sunulmuştur. 
Tablo 1: Analizde Kullanılan Değişkenler

\begin{tabular}{|c|c|c|c|}
\hline Değişkenin Adı & Değişkenin Tanımlanması & Elde Edildiği Kaynak & $\begin{array}{l}\text { Beklenti } \\
\text { İşaretleri }\end{array}$ \\
\hline \multirow[t]{2}{*}{ FDI } & Doğrudan Yabancı Yatırımlar (Milyon Dolar) & & \\
\hline & & OECD Database & \\
\hline ERS & Döviz Kuru İstikrarı & PRS, ICRG & + \\
\hline \multirow[t]{2}{*}{ TRD } & Ticari Dışa Açıklık & & + \\
\hline & (GSYH Yüzdesi Olarak) & Dünya Bankası, WDI & \\
\hline \multirow[t]{2}{*}{ POP } & Nüfus Artış Hızı & & + \\
\hline & (Yıllık \% Değişme) & Dünya Bankası, WDI & \\
\hline SE & Okullaşma, Yükseköğretim (brüt\%) & Dünya Bankası, WDI & + \\
\hline GS & Hükümet İstikrarı & PRS, ICRG & + \\
\hline SC & Sosyoekonomik Durum & PRS, ICRG & + \\
\hline IP & Yatırım Profili & PRS, ICRG & + \\
\hline IC & İç Karışıklık & PRS, ICRG & + \\
\hline EC & Dış Karışıklık & PRS, ICRG & + \\
\hline CR & Yolsuzluk & PRS, ICRG & + \\
\hline MP & Askeriyenin Politikaya Etkisi & PRS, ICRG & + \\
\hline $\mathbf{R P}$ & Dinsel Gerilimler & PRS, ICRG & + \\
\hline LO & Kanun ve Düzen & PRS, ICRG & + \\
\hline EP & Etnik Gerilimler & PRS, ICRG & + \\
\hline DA & Demokratik Sorumluluk & PRS, ICRG & + \\
\hline BQ & Bürokratik Kalite & PRS, ICRG & + \\
\hline PR & Politik Risk & PRS, ICRG & + \\
\hline
\end{tabular}

Doğrudan yabancı sermaye yatırımları OECD veri tabanından elde edilmiş olup logaritması alınarak kullanılmıştır. Doğrudan yabancı sermaye yatırımlarının ekonomik belirleyicileri olarak ise çalışmada ticari dışa açıklık, nüfus artış hızı, okullaşma oranı ve döviz kurunun istikrarı olmak üzere dört değişken kullanılmıştır. Ayrıca, çalışmada kurumsal göstergeler olarak politik risk ve on iki alt bileşeni kullanılmıştır.

Döviz kuru istikrarını gösteren ERS değişkeni, Politik Risk Servisi (PRS: Political Risk Services) tarafından hazırlanan ICRG endeksi verilerinden elde edilmiştir. Endeks değerlendirilmesinde bir takvim yılı veya geçmiş 12 aylık dönem için yerel para biriminin ABD doları karşısında değer kazanması veya kaybetmesi yüzde değişim olarak hesaplanır. İlgili değişken 0 ile 10 arasında değerler almakta olup yüksek değerler daha az değişimi ifade etmektedir. Döviz kurlarındaki yüksek oynaklık yatırımcılar için riskli bir ortam yarattığından, döviz kurundaki istikrarın doğrudan yabancı sermaye yatırımlarını pozitif olarak etkilemesi beklenmektedir.

Ticari dışa açıklık, ihracat ve ithalat toplamının GSYH'ye oranı olarak hesaplanmış olup Dünya
Bankası'nın World Development Indicators (WDI) veri tabanından elde edilmiştir. Dış açıklığın yüksek olması ilgili ülkenin dış dünya ile olan ticari entegrasyonunun yüksek olduğu anlamına gelmektedir. Dolayısıyla dışa açıklığın doğrudan yabancı sermaye yatırımlarına etkisinin pozitif olması beklenmektedir. Nüfus artış hızı, toplam nüfusun yıllık artış hızını ifade etmekte olup Dünya Bankası'nın WDI veri tabanından elde edilmiştir. Nüfusun artış oranının fazla olması, pazarın büyüklüğü ile ilişkilendirilmekte ve nüfus artışı yüksek olan ülkelerin daha fazla yabancı yatırım çektiği yaygın bir görüş olarak kabul edilmektedir. Dolayısıyla ilgili değişkenin beklenti işareti pozitiftir.

Yükseköğretimdeki okullaşma oranı Dünya Bankası'nın WDI veri tabanından elde edilen bir diğer değişkendir. Okullaşma oranı, yaşa bakılmaksızın ortaokuldan ayrıldıktan sonraki beş yıllık yaş grubunun toplam nüfusa yüzdesini ifade etmektedir. Yükseköğretimdeki okullaşma oranı beşeri sermayenin önemli göstergelerinden biridir. Beşeri sermayenin yüksek olması ise, doğrudan yabancı sermaye yatırımları ile ülkeye gelecek yüksek teknolojilere uyum sağlanması ve teknolojinin verimli bir şekilde kullanılması 
bakımından önem arz etmektedir. Bu doğrultuda yükseköğretimdeki okullaşma oranındaki bir iyileşme ülkenin beşeri sermayesini arttıracağından ilgili değişkenin doğrudan yabancı sermaye yatırımlarına etkisinin pozitif olması beklenmektedir.

Çalışmada politik istikrarın göstergesi olarak, ICRG endeksi verilerinden alınan "Politik Risk Endeksi" kullanılmıştır. Politik risk endeksi, ülkelerin siyasi ve sosyal özelliklerini kapsayan 12 farklı bileşeni içermektedir. Politik risk bileşenleri olarak adlandırılan her bir faktör belirlenen sınırlar arasında değerler almakta ve bu değerlerin toplanmasıyla ülke politik riski elde edilmektedir. Her bir risk faktörü için minimum puan 0 iken maksimum puan ise faktörlerin toplam risk değerlendirmesindeki ağırlığına bağlıdır (PRS, 2014: 2). Politik risk endeksindeki bileşenler ve bu bileşenlerin endeks içindeki puan ağırlıkları Tablo 2'de sunulmuştur.

Her bileşen için düşük değerler daha yüksek politik riski ifade ederken yüksek değerler daha düşük politik riski ifade etmektedir. Politik risk değerlendirmesinde maksimum puan 100 olup, bir ülkenin puanı ne kadar yüksek ise bu durum söz konusu ülkede politik riskinin o kadar düşük olduğunu göstermektedir. Ayrıca politik risk değerlendirmesinde; \%0 - \%49.9 puan aralığı "çok yüksek politik riski", \%50 - \%59 puan aralığı "yüksek politik riski", \%60 - \%69.9 puan aralığı "orta düzey politik riski", \%70 - \%79.9 puan aralığı "düşük politik riski" ve \%80 üzeri değerler "çok düşük politik riski" temsil etmektedir (PRS, 2014: 7).

Tablo 2: Politik Risk Değerlendirmesi

\begin{tabular}{|l|c|}
\hline Politik Risk Bileşenleri & Puan Ağırlıkları \\
\hline Hükümet istikrarı & 12 puan \\
Sosyoekonomik durum & 12 puan \\
Yatırım profili & 12 puan \\
İç karışılık & 12 puan \\
Dış karışılık & 12 puan \\
Yolsuzluk & 6 puan \\
Askeriyenin politikaya etkisi & 6 puan \\
Dinsel Gerilimler & 6 puan \\
Kanun ve düzen & 6 puan \\
Etnik gerilimler & 6 puan \\
Demokratik Sorumluluk & 6 puan \\
Bürokratik Kalite & 4 puan \\
\hline Toplam & 100 puan \\
\hline
\end{tabular}

Kaynak: PRS, 2013: 2

\section{TANIMLAYICI ISTATISTIKLER}

Çalışmada kullanılan değişkenlere ait temel tanımlayıcı istatistikler Tablo 3 ve Tablo 4'te sunulmuştur. Tablo 3'te değişkenlerin minimum ve maksimum değerleri ile bu endekslerin ortalama ve standart sapmalarına yer verilmiştir. Buna göre 1990-2012 yılları arasında OECD ülkelerinde doğrudan yabancı sermaye yatırımları ortalama olarak 18171.63 milyon dolar düzeyinde gerçekleşmiştir. Doğrudan yabancı sermaye yatırımlarının en yüksek değeri 2000 yılında ABD'de gerçekleşmişken en düşük değeri 2001 yılında İrlanda'da gerçekleşmiştir. Ülke paralarının ABD doları karşısındaki değişimini ifade eden reel döviz kurunun istikrarını gösteren ERS değişkeninin söz konusu yıllar arasındaki en düşük değeri 1.38 olarak 2001 yılında Türkiye'de gerçekleşmiştir. ERS 0 ile 10 arasında değerler almakta ve endeks değerinin sıfıra yaklaşması ülke paralarının ABD doları karşısında daha fazla değişim gösterdiği anlamına gelmektedir. Dışa açıklığın göstergesi olan ve ticaretin GSYH içindeki payını ifade eden TRD değişkenin en düşük değeri \%15.92 ile 1993 yılında Japonya'da gerçekleşmiş iken en yüksek değeri \%333.53 ile 2008 yılında Lüksemburg'da gerçekleşmiştir. Ülkelerdeki nüfus büyümesini ifade eden POP değişkenin en düşük değeri \%-1.03 olarak 1990 yılında Macaristan'da gerçekleşmiştir. İlgili değişkenin negatif değer alması nüfus azalışı olduğunu ifade etmektedir. POP değişkeninin en yüksek değeri ise \%2.53 ile 2007 yılında İzlanda'da gerçekleşmiştir. Yükseköğretimdeki okullaşma oranını temsil eden SE değişkenin ise söz konusu yıllar arasındaki en düşük değeri \%9.81 (Lüksemburg, 2000 yılı) iken en yüksek değeri \%97.09 (Kanada, 1992 yılı) olarak gerçekleşmiştir. 
Tablo 3: Tanımlayıcı İstatistikler

\begin{tabular}{lcccc} 
Değişkenler & Ortalama & Std. Sapma & Minimum & Maksimum \\
\hline FDI & 18171.63 & 37143.94 & $-31670,40$ & 321276 \\
ERS & 8.83 & 1.23 & 1.38 & 10 \\
TRD & 78.96 & 48.75 & 15.92 & 333.53 \\
POP & 0.67 & 0.58 & -1.03 & 2.53 \\
SE & 51.00 & 20.12 & 9.81 & 97.09 \\
PR & 80.56 & 11.43 & 43.5 & 96.08 \\
GS & 8.04 & 1.66 & 3.17 & 11.08 \\
SC & 7.70 & 1.73 & 2 & 11 \\
IP & 9.27 & 2.47 & 3 & 12 \\
IC & 10.74 & 1.34 & 4.25 & 12 \\
EC & 10.91 & 1.16 & 5.5 & 12 \\
CR & 4.44 & 1.19 & 2 & 6 \\
MP & 5.59 & 0.84 & 1 & 6 \\
RP & 5.49 & 0.71 & 2.5 & 6 \\
LO & 5.29 & 0.92 & 1.58 & 6 \\
EP & 4.77 & 1.05 & 2 & 6 \\
DA & 5.61 & 0.71 & 2 & 6 \\
BQ & 3.57 & 0.59 & 2 & 4 \\
& & & &
\end{tabular}

Politik riski temsil eden kurumsal değişkenleri endeks içindeki puan ağırlıkları bakımından üç gruba ayırarak incelemek mümkündür. Endeks değerleri 0 ile 12 arasında değişen değişkenler (hükümet istikrarı, sosyoekonomik durum, yatırım profili, iç karışıklık ve dış karışıklık) incelendiğinde, OECD ülkelerinde en düşük değerin sosyoekonomik durum bileşeninde gerçekleştiği dikkati çekmektedir. İlgili bileşenin en düşük değeri 1997 ve 1998 yıllarında Türkiye'de gerçekleşmiştir. Politik risk bileşenlerinde düşük değerler yüksek riski, yüksek değerler ise düşük riski temsil ettiğinden bu durum Türkiye'nin sosyoekonomik durum bakımından ülke grubu içinde en riskli konumda bulunan ülke olduğunu göstermektedir. Diğer yandan düşük riski temsil eden en yüksek değerlerin ise yatırım profili, iç karışıklık ve dış karışıklık bileşenlerinde gerçekleştiği dikkat çekmektedir. Analizin OECD ülkeleri için yapıldığı dikkate alındığında ortaya çıkan sonuç öngörüler doğrultusundadır. Endeks değerleri 0-6 arasında değişen değişkenler (yolsuzluk, askeriyenin politikaya etkisi, dinsel gerilimler, kanun ve düzen, etnik gerilimler, demokratik sorumluluk) incelendiğinde en düşük değerin askeriyenin politikaya etkisi bileşeninde gerçekleştiği görülmektedir. İlgili bileşenin en düşük değeri 1998-1999 yıllarında Türkiye'de gerçekleşmiştir. Bu durum Türkiye'nin askeriyenin politikaya etkisi bakımından ülke grubu içindeki en riskli konumda bulunan ülke olduğunu göstermektedir. Endeks değeri 0 ile 4 arasında değişen bürokratik kalite bileşenin en düşük değeri ise 2 olarak yine Türkiye'de gerçekleşmiştir. Bu durum, Türkiye'nin bürakratik kalite alanında da ele alınan ülke grubunda en riskli konumdaki ülke olduğunu göstermektedir. Diğer yandan 0 ile 100 arasında değişen değerler alan ve yukarıdaki bileşenlerin toplamını ifade eden politik risk değişkeninin ele alınan 29 OECD ülkesinde ortalama olarak 80.564 düzeyinde olduğu görülmektedir. İlgili değişkenin en düşük değeri 43.5 ile Türkiye'de gerçekleşmiş iken en yüksek değeri 96.08 ile Hollanda'da gerçekleşmiştir.

Çalışmada kullanılan değişkenlere ait korelasyon katsayıları Tablo 4'de sunulmuştur. Korelasyon tanımı gereği her hangi bir nedensellik ilişkisi göstermemekle beraber öncü bir gösterge olması bakımından önem taşımaktadır. Korelasyon analizi sonucuna göre, FDI ile modelin kontrol değişkenleri olan ERS, POP ve SE arasında pozitif bir korelasyon söz konusu iken TRD ile negatif bir korelasyon söz konusudur. Politik risk bileşenleri ile FDI arasındaki korelasyon sonuçları ise her bir alt bileşene bağlı olarak değişim göstermektedir. 


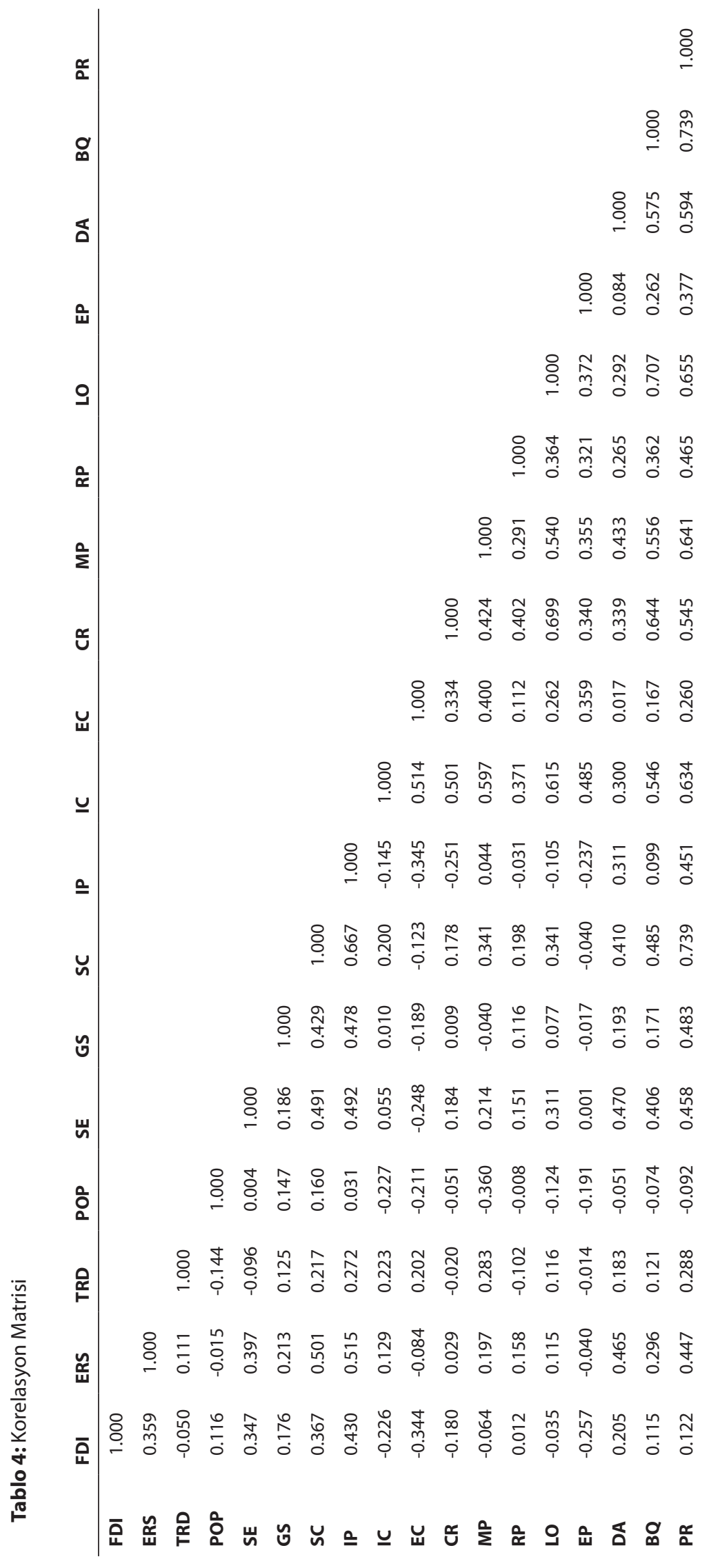




\section{EKONOMETRIK YÖNTEM VE ANALIZ SONUÇLARI}

Çalışmada doğrudan yabancı sermaye yatırımlarının ekonomik ve kurumsal belirleyicileri panel veri analiz yöntemi kullanılarak 1990-2012 döneminde 29 OECD ülkesi için incelenmiştir. Statik panel veri analizinde sabit ve tesadüfi etkiler yöntemleri kullanılabilmektedir. Bu yöntemlerden hangisinin kullanılacağına analiz edilen örneklemin özelliğine ve Hausman test sonucuna bakılarak karar verilmektedir. Çalışmada en uygun yöntemin sabit etkiler modeli olduğu tespit edilmiş ve kullanılmıştır. Analizde kullanılan model aşağıdaki gibidir;

$$
\begin{aligned}
& L F D I_{i t}=\alpha_{i}+\lambda_{t}+\beta_{1} E R S_{i t}+\beta_{2} T_{R D}+ \\
& \beta_{3} P O P_{i t}+\beta_{4} S E_{i t}+\beta_{5} P R B_{i t}+\varepsilon_{i t} \\
& \mathrm{i}=1, \ldots, \mathrm{N} ; \mathrm{t}=1, \ldots, \mathrm{T}
\end{aligned}
$$

(1) nolu denklemde; i ve t sırasıyla ülke ve zamanı, $\beta$ tahmin katsayılarını, $\alpha_{i}$ ülke sabit etkisini, $\lambda_{t}$ zaman sabitini, $\varepsilon_{i t}$ hata terimini, L ise ilgili değişkenin logaritmasının alındığını ifade etmektedir. Ayrıca PRB, politik riski ve politik riskin alt bileşenlerini temsil etmektedir.

Çalışmada çoklu doğrusal bağlantı sorunundan kaçınmak için politik riski oluşturan alt bileşenlerin her biri ayrı ayrı modellenmiştir. Bu doğrultuda 14 farklı model oluşturulmuştur. Birinci modelde sadece doğrudan yabancı sermaye yatırımlarının ekonomik belirleyicilerine yer verilirken diğer modellerde politik risk ve politik riski oluşturan her bir alt bileşen ayrı ayrı analiz edilmiştir. Ayrıca yapılan tahminler sonrasında tüm modellerde otokorelasyon sorunu ile karşılaşılmış olduğundan daha güvenilir sonuçlar elde etmek amacıyla AR(1) süreci ile otokorelasyon sorunu giderilmiştir. Modellere ait analiz sonuçları Tablo 5'de yer almaktadır.
Doğrudan yabancı sermaye yatırımlarının sadece ekonomik belirleyicilerinin yer aldığı 1. Model sonuçlarına bakıldığında, tüm değişkenlerin anlamlı ve işaretlerinin teorik beklentiyle uyumlu olduğu görülmektedir. Devam eden 13 modelde, ekonomik belirleyicilerin yanı sıra kurumsal göstergeleri ifade eden politik risk ve politik riskin alt bileşenleri yer almaktadır. Bu modellerin sonuçları incelendiğinde, dış karışıklık ve demokratik sorumluluk değişkenlerinin yer aldığı 6. ve 12. model dışındaki tüm modellerde politik risk bileşenlerinin anlamlı ve pozitif olduğu dikkati çekmektedir. Bu doğrultuda; hükümet istikrarı, sosyoekonomik durum, dinsel gerilimler ve kanun ve düzen değişkenleri istatistiki olarak \%1 seviyesinde; yatırım profili, iç karışıklık, askeriyenin politikaya etkisi ve bürokratik kalite değişkenleri istatistiki olarak \%5 seviyesinde; yolsuzluk ve etnik gerilimler değişkenleri ise istatistiki olarak \%10 seviyesinde anlamlı bulunmuştur. Elde edilen sonuçlara göre OECD ülkelerinde; hükümet istikrarı, sosyoekonomik durum, yatırım profili, iç karışıklık, askeriyenin politikaya etkisi, dinsel gerilimler, kanun ve düzen, etnik gerilimler ve bürokratik kalite ile doğrudan yabancı sermaye yatırımları arasında pozitif yönlü bir ilişki söz konusudur. Başka bir anlatımla politik risk bileşenlerinin endeks değerlerindeki bir yükselme doğrudan yabancı sermaye yatırımlarını arttırmaktadır. Diğer yandan tüm bileşenlerin toplamından oluşan politik risk değişkeni ile doğrudan yabancı sermaye yatırımları arasında pozitif ve istatistiki olarak \%1 seviyesinde anlamlı bir ilişki söz konusudur. Bu sonuç ele alınan ülke grubunda ülke politik riski ile doğrudan yabancı sermaye yatırımları arasında doğru yönlü bir ilişki olduğunu göstermektedir. 


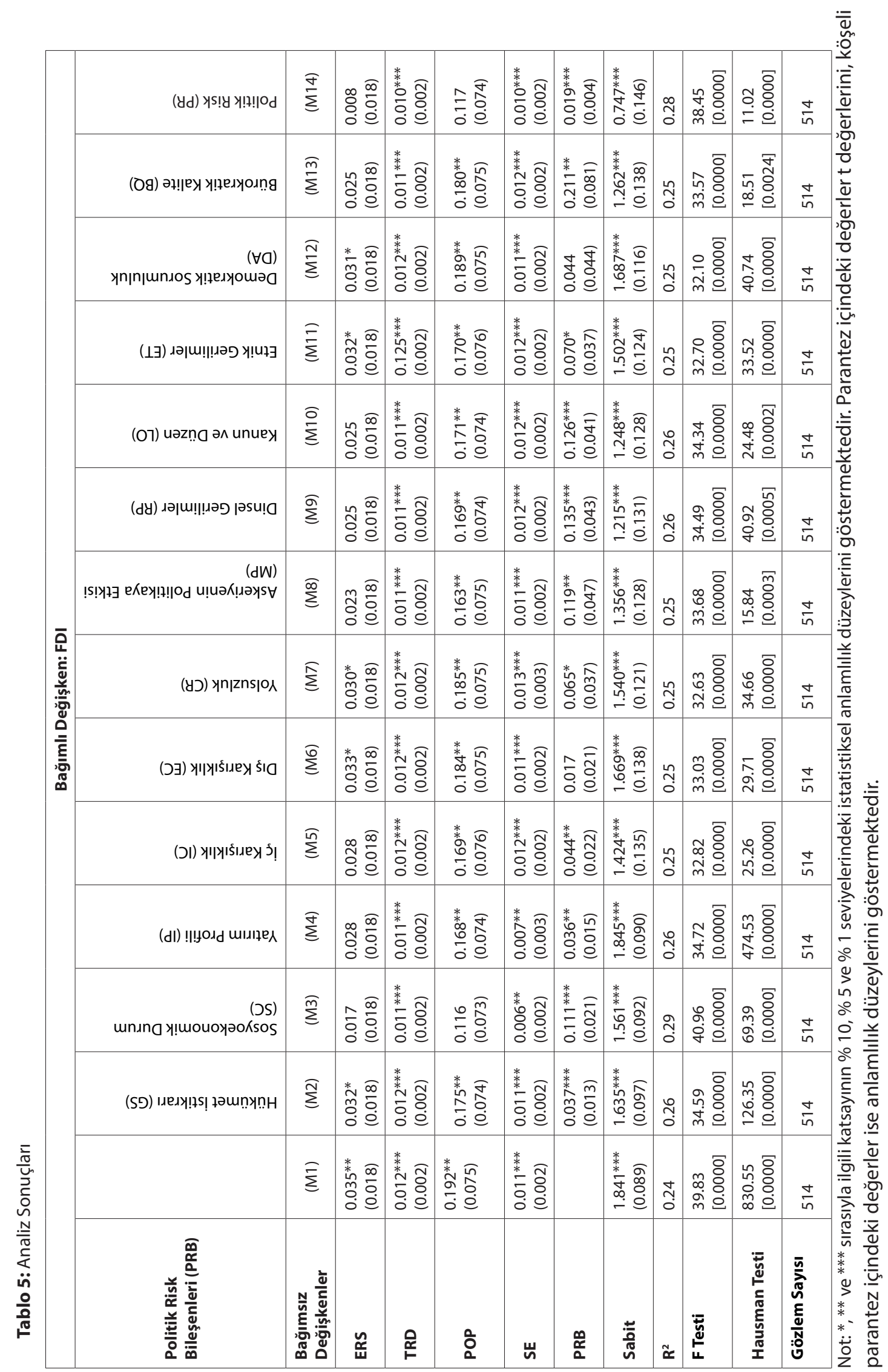




\section{GENEL DEĞERLENDIRME VE SONUÇ}

Literatürde doğrudan yabancı sermaye yatırımlarının belirleyicilerini açıklamaya yönelik pek çok çalışma olmasına rağmen bu çalışmalarda daha çok ekonomik faktörlere odaklanılmıştır. Bunun yanında son yıllarda az sayıda da olsa doğrudan yabancı sermaye yatırımlarının kurumsal belirleyicilerine yönelik çalışmaların ön plana çıktığı görülmektedir. Bu çalışmada, nispeten yüksek gelir ve kaliteli kurumsal yapıya sahip olan OECD ülkelerinde ekonomik ve kurumsal faktörlerin doğrudan yabancı sermaye yatırımları üzerindeki etkileri 1990-2012 dönemi için analiz edilmiştir. Kurumsal yapının göstergesi olarak ICRG'den temin edilen politik risk ve politik riskin 12 alt bileşeni kullanılmıştır. Elde edilen bulgulara göre; politik risk ve alt bileşenler olan hükümet istikrarı, sosyoekonomik durum, yatırım profili, iç karışıklık, askeriyenin politikaya etkisi, dinsel gerilimler, kanun ve düzen, etnik gerilimler ve bürokratik kalite ile doğrudan yabancı sermaye yatırımları arasında pozitif yön- lü bir ilişki söz konusudur. Yani kurumsal yapıdaki bir iyileşme doğrudan yabancı sermaye girişlerini olumlu yönde etkilemektedir. Ancak, kurumsal yapının kalitesini ölçmek amacıyla ayrı ayrı modellenen kurumsal değişkenlerden bürokratik kalite, dinsel gerilimler, kanun ve düzenin doğrudan yabancı sermaye yatırımları üzerindeki etkisi diğer kurumsal göstergelere göre daha yüksek tespit edilmiştir.

Çalışmadan elde edilen sonuçlar, literatürde kaliteli kurumsal yapının belirsizlikleri ortadan kaldırarak işlem maliyetlerini düşüreceği ve böylece yatırımlar için elverişli bir ortam yaratacağı görüşünü destekler niteliktedir. Bu sonuç politika uygulayıcılarına, daha çok doğrudan yabancı sermaye yatırımları çekmek ve doğrudan yabancı sermaye yatırımlarının pozitif dışsallıklarından yararlanmak için mutlak surette kurumsal kalitelerini geliştirmeleri gereğini göstermektedir. 


\section{SON NOTLAR}

${ }^{1}$ Belçika ve Güney Kore’ye ait bazı verilerin elde edilememesi; Estonya, İsrail ve Slovenya'nın ise 2010 yılında OECD üyesi olması dolayısıyla çalışma kapsamına alınmamıslardır.

2 Araştırma kapsamında yer alan 29 OECD ülkesi; Avustralya, Avusturya, Kanada, Şili, Çek Cumhuriyeti,
Danimarka, Finlandiya, Fransa, Almanya, Yunanistan, Macaristan, İzlanda, İrlanda, İtalya, Japonya, Lüksemburg, Meksika, Hollanda, Yeni Zelanda, Norveç, Polonya, Portekiz, Slovakya, İspanya, İsveç, İsviçre, Türkiye, İngiltere ve Amerika Birleşik Devletleri'dir.

\section{KAYNAKLAR}

Acemoğlu, Daron (2009) Introduction to Modern Economic Growth, Princeton University Press.

Acemoğlu, Daron ve Diğerleri (2003) "Institutional Causes, Macroeconomic Symptoms Volatility, Crises and Growth" Journal of Monetary Economics, 50, 49-123.

Acemoğlu, Daron ve Robinson, James (2012) Why Nations Fail: The Origins of Power, Prosperity and Poverty, New York: Crown Publishers.

Anghel, Brindusa (2005) "Do Institutions Affect Foreign Direct Investment?” International Doctorate in Economic Analysis, Universidad Autónoma de Barcelona, http://idea.uab.es/abrindusa/research/paper FDI and institutions.pdf

Antonakakis, Nikolaos ve Tondl, Gabriele (2011) "Do Determinants of FDI to Developing Countries Differ among OECD Investors? Insights from Bayesian Model Averaging" FIW Working Paper No. 76.

Azam vd. (2010) "Institutional and Macro Economic Policy Factors on Foreign Direct Investment: South Asian Countries Case" African Journal of Business Management, 5(11): 4306-4313.

Azemar, C. ve Desbordes, R. (2009) "Short-Run Strategies For Attracting Foreign Direct Investment” Working Papers 24, Department of Economics, University of Glasgow.

Barrell, R. ve Pain, N. (1997) "Foreign Direct Investment, Technological Change, and Economic Growth within Europe" The Economic Journal, 107(445): 17701786.

Bellak, C., Leibrecht, M. ve Riedl, A. (2008) "Labor Costs and FDI Flows into Central and Eastern European Countries: A Survey of the Literature and Empirical Evidence" Structural Change and Economic Dynamics, 19(1): 17-37.

Benassy-Quere, Agnès; Coupet, Maylis ve Mayer, Thierry (2007) "Institutional Determinants of Foreign
Direct Investment" The World Economy, 767-782.

Billington, N. (1999) "The Location of Foreign Direct Investment: An Empirical Analysis” Applied Economics, 31: 65-76.

Busse, M. ve Hefeker, C. (2007) "Political Risk, Institutions and Foreign Direct Investment" European Journal of Political Economy, 23(2): 397-415.

Campos, N. F., Kinoshita ve Y. (2008) "Foreign Direct Investment and Structural Reforms: Evidence from Eastern Europe and Latin America" IMF Working Papers 08/26, International Monetary Fund.

Culem, C. (1988) "The Locational Determinants of Direct Investments among Industrialized Countries" European Economic Review, 32(4): 885-904.

Daniele, Vittorio ve Marani, Ugo (2006) "Do Institutions Matter for FDI? A Comparative Analysis of the MENA Countries” MPRA Paper No. 2426.

Dawson, John W. (2003) "Causality in the FreedomGrowth Relationship" European Journal of Political Economy, 19: 479-495.

Dawson, John W. (2010) "Macroeconomic Volatility and Economic Freedom-A Preliminary Analysis" Economic Freedom of the World: 2010 Annual Report, 175185.

De Haan, Jakob ve Siermann, Clemens L. J. (1995) "New Evidence on the Relationship Between Democracy and Economic Growth", Public Choice, 86(1-2): 175-198.

De Haan, Jakob ve Siermann, Clemens L. J. (1998) "Further Evidence on the Relationship Between Economic Freedom and Economic Growth", Public Choice, 95(3-4): 363-380.

Del Bo, Chiara (2009) "Foreign Direct Investment, Exchange Rate Volatility and Political Risk”, http://www. etsg.org/ETSG2009/papers/delbo.pdf

Demirtaş, Gökhan ve Akçay, Selçuk (2006) "Kurum- 
sal Faktörlerin Doğrudan Yabancı Yatırımlar Üzerine Etkisi: Ampirik Bir Kanı"” Gazi Üniversitesi İktisadi ve İdari Bilimler Fakültesi Dergisi, 8/2, 15-33.

Easterly, William (2005) "National Policies and Economic Growth: A Reappraisal", P. Aghion ve S. Durlauf (Ed.), Handbook of Economic Growth, 1A, Elsevier, B.V.

Edwards, S. (1990) "Capital Flows, Foreign Direct Investment, and Debt-Equity Swaps in Developing Countries" National Bureau of Economic Research, Working Paper No 3497.

Gast, Michael ve Herrmann, Roland (2008) "Determinants of Foreign Direct Investment of OECD Countries 1991-2001" International Economic Journal, 22(4): 509-524.

Gastanaga, Victor, Jeffrey Nugent ve Bistra, Pashamova (1998) "Host Country Reforms and FDI Inflows: How Much Difference Do They Make?" World Development, 26(7): 1299-1314.

Gedik, Melek Akdoğan (2013) "Determinants of Foreign Direct Investment for OECD Countries: Evidence from Dynamic Panel Data Analysis" British Journal of Economics, Finance and Management Sciences, 7(2): 119140.

Grogan, Louise ve Moers, Luc (2001) "Growth Empirics with Institutional Measures for Transition Countries" Economic Systems, 25: 323-344.

Hall, Robert E. ve Jones, Charles I. (1999) "Why Do Some Countries Produce So Much More Output per Worker than Others?" The Quarterly Journal of Economics, 114(1): 1-50.

Hausmann, R. ve E. Fernandez-Arias (2000) "Foreign Direct Investment: Good Cholesterol?” Inter-American Development Bank, Research Department Working Paper 417, Washington D.C.

Khan, Mashrur Mustaque ve Akbar, Mashque Ibne (2013) "The Impact of Political Risk on Foreign Direct Investment” MPRA Paper No. 47283.

Knack, Stephen ve Keefer, Philip (1997) "Does Social Capital Have an Economic Pay Off? A Cross-Country Investigation" The Quarterly Journal of Economics, 112(4): 1251-1288.

Konings, J. ve Murphy, A. P. (2006) “Do Multinational Enterprises Relocate Employment to Low-Wage Regions? Evidence from European Multinationals" Review of World Economics 142(2): 267-286.

Loree, D., Guisinger, S. E. (1995) "Policy and NonPolicy Determinants of U.S. Equity Foreign Direct In- vestment" Journal of International Business Studies, 26: 281-300.

Moore, M.O. (1993) "Determinants of German Manufacturing Direct Investment in Manufacturing Industries” Weltwirtschaftliches Archiv, 129: 120-137.

Moosa, Imad A. (2009) "The Determinants of Foreign Direct Investment in Mena Countries: An Extreme Bounds Analysis" Applied Economics Letters, 16: 15591563.

Noorbakhsh, F., Paloni, A. ve Youssef, A. (2001) "Human Capital and FDI Inflows to Developing Countries: New Empirical Evidence" World Development, 29(9): 1593-1610.

PRS (2014) "International Country Risk Guide Methodology"

Schneider, Friedrich (1985) "Economic and Political Determinants of Foreign Direct Investment" World Development, 13(2): 161-175.

Sekkat, Khalid ve Veganzones-Varoudakis, Marie-Ange Veganzones (2004) "Trade and Foreign Exchange Liberalization, Investment Climate and FDI in the MENA Countries" Centre National de la Recherche Scientifique, CERDI, Clermont Ferrand, France and World Bank, Washington D.C., USA.

Sekkat, Khalid ve Veganzones-Varoudakis, Marie-Ange Veganzones (2007) "Openness, Investment Climate, and FDI in Developing Countries" Review of Development Economics, 11(4): 607-620.

Sin, C.Y. ve Leung, W.F. (2001) "Impacts of FDI Liberalization on Investment Inflows", Applied Economics Letters, 8: 253-256.

Stein Ernesto ve Daude, Christian (2001) "Institutions, Integration, and the Location of Foreign Direct Investment" Washington DC, United States: Inter-American Development Bank.

Wheeler, David ve Mody, Ashoka (1992) "International Investment Location Decisions: The Case of U.S. Firms" Journal of International Economics, 33: 57-76. 